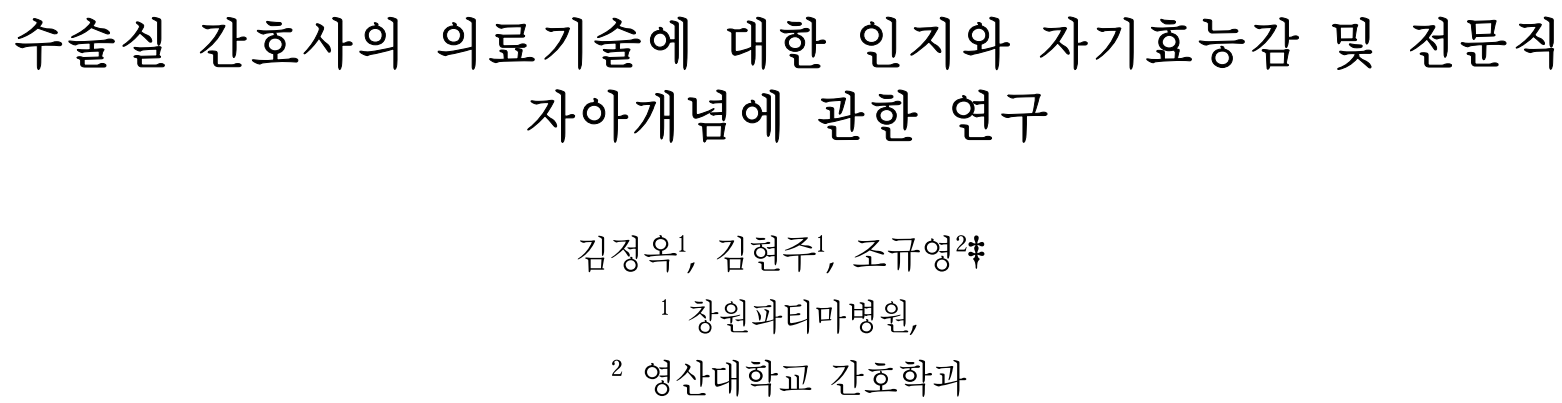

\title{
A Study on the Perception of Medical Technology, Self Efficacy and Professional Self-Concept among Operating Nurses
}

\author{
Jeong-ok Kim¹, Hyun-Ju Kim¹, Gyoo-yeong $\mathrm{Cho}^{2 \neq}$ \\ ${ }^{1}$ Changwon Fatima Hospital \\ ${ }^{2}$ Department of Nursing Youngsan university
}

\begin{abstract}
$<$ Abstract $>$
The purpose of this study was to investigates the perception on medical technology, self-efficacy, and professional self conception of OR nurses. The data was collected by distributing structured questionnaires to $164 \mathrm{OR}$ nurses in 13 secondary hospitals located in Gyeongsangnam-do and Gyeongsangbuk-do, beginning Apr. 12th to the 24th of 2010, and analyzed by t-test, ANOVA, Pearson correlation coefficient. The correlation between perception on medical technology and professional self conception showed to be positively correlated at $r=.222$. The correlation between self-efficacy and perception on medical technology showed positive correlation at $r=.197$. Also, the correlation between self-efficacy and professional self conception was $r=.609$, showing a relatively high positive correlation. We have observed that the perceptions of nurses on medical technology and their self efficacy have a significant effect in professional self consciousness. Therefore, it is important to develop programs that increase self-efficacy and followed by policies to maintain them.
\end{abstract}

Key Words : Perception of Medical Technology, Self Efficacy, Professional Self-concept, Operating Nurses 


\section{I. 서론}

\section{1. 연구의 필요성}

의료의 질 향상과 환자의 안전에 핵심가치를 둔 의료시장의 확대와 효율성 증대를 위해 의료기술 을 지속적으로 도입하고 있는 최근의 의료계는 국 민 소득수준 향상과 의료서비스의 질적 향상으로 인해 의료인인 공급자 주도에서 환자인 소비자 주 도로 변화하고 있으며 소비자들은 자신이 받게 될 의료 서비스를 결정하는 것에 적극적으로 참여하 게 되었다[1]. 이로 인해 의료제공자와 의료 소비 자 사이의 의사소통이 원활해지면서 의료 서비스 제공자는 보건의료 전달체계의 변화에 발맞추기 위해 신의료기술 도입에 보다 적극적으로 변화하 게 되었다.

새로운 의료기술은 로봇과 인공장기, 각종 복강 기기와 의약품 및 의료소모품, 모든 종류의 디지털 화와 시공을 초월해 의사소통을 할 수 있는 네트 워크 시스템, 환자상태 모니터링 시스템, 바이오기 술, 나노기술, 아직 실험단계에 있는 모든 수술 방 법 등을 포함한다[2]. 이러한 변화에 효과적으로 대응하기 위해서는 전문 직업인으로서의 긍정적인 직업관 및 자신감을 가지고 새로운 변화에 적절하 게 대응하는 간호사의 역할이 중요하다.

특히, 수술실은 독립된 특수부서로서 많은 수의 간호사들이 근무하고 있으며 일반 병동 간호사와 는 전혀 다른 역할과 방식으로 근무하고 있다. 더 욱이 최근에는 수술의 종류, 방법, 내용, 장비 및 기구 등이 다양화되고 계속 발전하므로 수술실 간 호사는 보다 더 전문화된 간호지식과 복잡한 특수 기술이 요구되는 전문인으로서 역할을 담당하게 되며[3], 매일 새롭게 개발되고 수술에 반영되는 의료 기술의 도입은 수술실 간호사에게 충분한 지 식과 기술뿐만 아니라 새로운 의료기술을 배우려 는 의지, 수술실 팀원 간의 분위기 조성과 팀워크
향상 등의 다양한 도전과제를 요구하고 있다.

따라서 의료 전문인으로서의 업무수행을 다하기 위해 지속적인 교육을 통한 새로운 지식과 기술의 확보와 신기술습득에 대한 긍정적인 인지가 필요 하다. 또한 의료기술에 대한 긍정적인 인지는 전문 직 자아개념과 자기효능감에 중요한 영향을 미칠 것으로 기대된다.

간호사들의 전문직 자아개념은 스스로 자신에 대한 이해와 견해가 긍정적일 때 향상되며, 양질의 수술간호 업무와 전인간호의 실천을 위해서는 수 술실 간호사 자신의 긍정적인 자아개념 정립이 중 요하다. 즉, 간호사는 간호직에 대한 자신감 및 책 임감을 가져야 하고, 간호 대상자에게 전인적이고 질적인 간호를 제공할 수 있어야 하며, 직무를 효 율적으로 수행하기 위해서는 직업에 대한 신념, 태 도, 지각 등이 중요한 작용을 하게 된다[4].

또한 전문직 자아개념과 자아성취감에 영향을 주는 자기효능감은 임상 간호사의 연구 활동을 자 극하기 위한 원동력이 되며 간호현장에서 행동하 는 개개인의 활동에 대한 동기와 변화를 줄 수 있 다고 보고되고 있다[5]. 그러므로 특정 상황에서 학습할 때 학습자가 기울이는 노력과 의지는 자신 이 주어진 상황에서 학습을 잘 할 수 있을 것이라 는 자기 확신 또는 자신감에 영향을 받으며, 자기 효능감이 높은 간호사는 빠르게 도입되는 의료기 술의 습득 과정에서 자신의 학습을 성공적으로 이 끌기 위해서 적극적으로 활동하고자 하는 의지를 보일 것으로 기대된다. 이처럼 자기효능감은 조직 행동 연구에서 매우 중요한 연구 주제로 부상하고 있는데 그 이유는 자기효능감이 조직의 성과 및 구성원들의 동기부여와 강력한 연결 관계를 지니 고 있음이 점차 확인되고 있기 때문이다[6]. 특히 많은 시간을 직장에서 보내는 간호사의 경우 자기 효능감은 독자적이고 전문적인 업무수행에 커다란 영향을 준다고 할 수 있다.

간호사의 자기효능감과 전문직 자아개념은 최은 
영과 김건효[7], 장희정 등[8], 이경희[9], 이승희[10] 등의 선행연구에서 자기효능감이 높을수록 전문직 자아개념이 높게 나타나 긍정적인 전문직 자아개 념을 형성하는데 있어 자기 효능감이 중요함을 시 사하였다. 이에 비해 의료기술과 관련된 노춘희와 송경애[11][12], 노춘희 등[13]의 연구가 있으나, 일 부의 연구자에 한해서 연구가 이루어지고 있으며, 의료기술에 대한 인지와 자기효능감 및 전문직 자 아개념과의 관계를 조사한 연구는 이경희[9]이외에 는 연구가 미흡한 현실이다.

따라서 본 연구는 변화하는 의료 환경에 능동적 으로 대처할 수 있어야 하는 수술실 간호사를 대 상으로 의료기술에 대한 인지, 자기 효능감과 전문 직 자아개념을 파악하고, 각 변수들간의 관계 를 알아봄으로써 미래의 첨단 의료기술 발달에 대처 하고, 수술환자 간호의 질적 향상을 도모하기 위한 기초자료를 제공하고자 한다.

\section{2. 연구의 목적}

본 연구는 수술실 간호사의 의료기술에 대한 인 지와 자기효능감 및 전문직 자아개념을 파악하고, 각 변수들 간의 상관관계를 알아봄으로써 수술환 자 간호의 질적 향상을 위한 기초자료를 제공하고 자 하였으며, 본 연구의 구체적인 목적은 다음과 같다.

1) 수술실 간호사의 의료기술에 대한 인지와 자 기효능감 및 전문직 자아개념을 파악한다.

2) 수술실 간호사의 일반적 특성 및 교육여부에 따른 의료기술에 대한 인지와 자기효능감 및 전문 직 자아개념의 차이를 파악한다.

3) 수술실 간호사의 의료기술에 대한 인지와 자 기효능감 및 전문직 자아개념의 상관관계를 파악 한다.

\section{II. 연구 방법}

1. 연구 대상

본 연구의 대상은 연구자의 편의에 의해 경남 경북 지역에 소재하는 13 개의 병원급 의료기관 수술실에 근무하는 간호사로서 연구 참여에 동의 한 164 명을 대상으로 하였다.

2. 연구 도구

1) 의료기술에 대한 인지

의료기술이란 제공된 의료체계 하에서 보건의료 와 조직, 지지조직에서 사용되는 약, 장치, 의료 및 수술절차를 말하며[14], 본 연구에서의 의료기술은 의료행위 자체만 의미하는 것이 아니라 의약품, 의 료장비, 의료소모품, 의료 지원체계를 모두 포함한 다.

의료기술에 대한 인지 측정도구는 Arthur 등 [17]이 개발한 의료기술 발달의 영향을 측정하는 도구(Technology Influences Questionnaire, TIQ)를 노춘희와 송경애가 번안하여[11] 수정, 보완한 도 구를 이용하여 측정하였다. 이 도구는 총 14 문항으 로 구성된 Likert 5점 척도로서 "그렇지 않다."에 1점, "그렇지 않은 편이다."에 2점, "잘 모르겠다." 에 3점, "그런 편이다."에 4점, "그렇다."에 5점으 로 환산하였으며, 8 문항의 부정적 문항은 역산하였 다. 14 문항의 총점은 최저 14 점에서 최고 70 점으 로, 점수가 높을수록 의료기술 발달이 간호현장에 미친 영향이 긍정적으로 인지되고 있음을 의미한 다.

개발당시 신뢰도는 Cronbach's a $=.75$ 이었고 본 연구에서는 Cronbach's $a=.71$ 이었다.

2) 자기 효능감

개인이 어떤 결과를 산출하기 위해 요구되는 행 
동을 성공적으로 수행할 수 있다는 신념으로, 주어 진 업무를 성취하기 위해 필요한 행동을 조직하고 수행하는 자신의 능력에 대한 판단이다[15].

자기 효능감의 측정 도구는 Sherer 등[18]이 개 발하고 정애순[19]이 수정, 보완한 도구를 이용하 여 측정하였다. 이 도구는 총 17 문항으로 구성된 Likert 5점 척도로서 "그렇지 않다."에 1점, "그렇 지 않은 편이다."에 2점, "잘 모르겠다."에 3점, "그런 편이다."에 4점, "그렇다."에 5점으로 환산하 였다. 17 문항의 총점은 최저 17 점에서 최고 85 점으 로, 점수가 높을수록 수술실 간호사의 자기효능감 이 높음을 의미한다. 개발당시 신뢰도는 Cronbach's $a=.71$ 이었고 본 연구에서는 Cronbach's $a=.90$ 이었다.

3) 전문직 자아개념

전문직 직업인으로서의 자신에 대한 정신적 지 각(mental perception)으로, 특히 자신의 업무에 대 한 스스로의 느낌과 견해를 의미한다[16].

전문직 자아개념 측정도구는 Arthur[16]가 개발 한 간호사의 전문직 자아개념 측정도구 (Professional Self-Concept of Nurse Instrument, $\mathrm{PSCNI}$ )를 송경애와 노춘희[20]가 번안하고 김수연 [4]이 수정 보완한 도구를 이용하여 측정하였다. 이 도구는 전문적 실무 16 문항(지도력 4 문항, 기술 5 문항, 융통성 7 문항), 만족감 7 문항, 의사소통 4 문 항의 세 영역, 총27문항으로 구성된 Likert 4점 척 도로서"그렇지 않다."에 1점, "그렇지 않은 편이 다."에 2점, “그런 편이다."에 3점, "그렇다."에 4점 으로 환산하였으며, 4 문항의 부정문항은 역산 하였 다. 27 문항의 총점은 최저 27점에서 최고 108점으 로, 점수가 높을수록 전문직 자아개념이 높음을 의 미한다. 개발 당시 신뢰도는 Cronbach's $a=.85$ 이 었고, 본 연구에서는 Cronbach's $a=.86$ 이었다.
3. 자료 수집 및 방법

자료 수집 기간은 2010년 4월 12일부터 2010년 4 월 24 일까지 12 일간이었으며, 자료 수집 방법은 연구자가 대상병원의 간호부 또는 수술실에 연락 하여 연구의 목적과 취지를 설명하고, 연구 승인을 받은 후 우편과 직접방문을 병행하여 각 수술실의 교육담당자를 통해 연구에 참여할 것을 동의한 수 술실 간호사들에게 설문지를 배부한 후 회수하였 다. 배부한 설문지는 총 170 부였고 회수된 것은 166 부로 회수율은 $97.64 \%$ 였으며, 이 중 응답이 불 충분한 설문지 2 부를 제외한 164 부를 최종분석에 사용하였다.

\section{4. 자료 분석}

수집된 자료는 부호화하여 SPSS Version 12를 이용하여 전산 처리하였다.

1) 일반적 특성과 교육여부에 따른 의료기술 대 한 인지, 자기효능감, 전문직 자아개념의 차이 는 t-test, ANOVA, Scheffe 사후검정을 이용하여 유의성을 분석하였다.

2) 의료기술 대한 인지, 자기효능감, 전문직 자 아개념과의 상관관계는 피어슨 상관계수(Pearson's Correlation coefficient)로 분석하였다.

\section{III. 연구결과}

\section{1. 수술실 간호사의 일반적 특성}

수술실 간호사의 일반적 특성은 <표 1 >과 같다. 수술실 간호사의 성별은 여자 $97 \%$, 남자 3\%로 분포하였으며, 평균연령은 29 세이고 연령분포는 2 0 29세가 $64.6 \%, 30 \sim 39$ 세가 $27.4 \%, 40$ 세 이상이 
$7.9 \%$ 순이였다. 결혼 상태는 미혼이 $64.6 \%$, 기혼이 $35.4 \%$ 였으며, 종교는 있음이 $50.6 \%$, 없음이 $49.4 \%$ 였다. 전문대 졸업이 $72.6 \%$, 학사 졸업 및 석사 과 정 이상이 $27.4 \%$ 였으며, 수술실에서의 직위는 일반 간호사가 $82.9 \%$, 책임간호사 및 수간호사가 $18.1 \%$ 였다. 수술실 근무경력은 평균 6년 3개월로 1 5년 미만이 $42.1 \%, 5 \sim 10$ 년 미만이 $26.8 \%, 10$ 년 이상이 $20 \%, 1$ 년 미만이 $11 \%$ 였다.

\begin{tabular}{|c|c|c|c|}
\hline \multicolumn{2}{|r|}{ 범주 } & \multicolumn{2}{|c|}{ 명(\%) } \\
\hline \multirow[t]{2}{*}{ 성별 } & 남 & 5 & $\begin{array}{l}(3.0) \\
\end{array}$ \\
\hline & 여 & 159 & (97.0) \\
\hline \multirow[t]{3}{*}{ 연령(세) } & 29세 이하 & 106 & $(64.6)$ \\
\hline & 30 39 & 45 & (27.4) \\
\hline & 40세 이상 & 13 & (7.9) \\
\hline 평균 연령 & & 29.3 & $7 \pm 5.78$ \\
\hline \multirow[t]{2}{*}{ 결혼여부 } & 기혼 & 58 & (35.4) \\
\hline & 미혼 & 106 & $(64.6)$ \\
\hline \multirow[t]{2}{*}{ 종교 } & 유 & 83 & $(50.6)$ \\
\hline & 무 & 81 & (49.4) \\
\hline \multirow[t]{3}{*}{ 교육정도 } & 전문대 & 119 & $(72.6)$ \\
\hline & 학사졸 이상 & 45 & (27.4) \\
\hline & 1년 미만 & 18 & (11.0) \\
\hline \multirow{3}{*}{$\begin{array}{l}\text { 수술실 } \\
\text { 근무경력(년) }\end{array}$} & 1 5년 & 69 & $(42.1)$ \\
\hline & 5 10년 & 44 & (26.8) \\
\hline & 10년 이상 & 33 & (20.0) \\
\hline \multirow{3}{*}{$\begin{array}{l}\text { 평균근무경력(웍)윌 } \\
\text { 웍) }\end{array}$} & & 75.95 & \pm 63.37 \\
\hline & 수간호사 및 책임감호사 & 28 & (18.1) \\
\hline & 일반간호사 & 136 & (82.9) \\
\hline \multirow{3}{*}{$\begin{array}{l}\text { 초기 의료기술 } \\
\text { 교육여부 }\end{array}$} & 실시한다 & 127 & (77.4) \\
\hline & 실시하지 않는다 & 11 & $(6.7)$ \\
\hline & 일부관리자만 한다 & 26 & (15.9) \\
\hline \multirow{2}{*}{$\begin{array}{l}\text { 계속 의료기술 } \\
\text { 꾜육여부 }\end{array}$} & 실시한다 & 137 & (83.5) \\
\hline & 실시하지 않는다 & 27 & (16.5) \\
\hline 교육매뉴얼 & 비치되어 있다 & 135 & (82.3) \\
\hline 비치여부 & 비치되어 있지 않다 & 29 & $(17.7)$ \\
\hline
\end{tabular}

수술실의 의료기술 도입 시 교육 실시 여부에 대해서는 실시한다가 $77.4 \%$ 로 가장 높게 분포하였 으며, 일부 관리자만 한다가 $15.9 \%$, 실시하지 않는 다가 $6.7 \%$ 의 순이였으며, 의료기술에 관한 계속적 인 교육 시행 여부를 살펴보면 그렇다가 $83.5 \%$, 그
렇지 않다가 $16.5 \%$ 였다. 또한 교육 매뉴얼의 비치 여부에 대해서는 비치되어 있다가 $82.3 \%$, 비치되어 있지 않다가 $17.7 \%$ 였다.

2. 수술실 간호사의 의료기술에 대한 인지와 자기효능감 및 전문직 자아개념의 정도

수술실 간호사의 의료기술에 대한 인지와 자기 효능감 및 전문직 자아개념의 정도는 <표 $2>$ 와 같다.

수술실 간호사의 의료기술에 대한 인지 정도는 최저 32점에서 최고 68점이었으며, 평균점수는 총 70점 만점에 $47.88 \pm 5.78$ 점이었으며, 평균 평점은 5 점 만점에 3.42점으로 나타났다.

항목별로 세부적으로 분석하여 보면 <표 3>과 같이 제시할 수 있는데, 고도로 발달된 수술 의료 기술의 도입 시 거기에 합당한 숙련된 기술이 필 요하다가 4.47점으로 가장 높게 나타났으며, 의료 기술을 능숙하게 활용하는 것은 수술실 간호사가 전문직업인으로서의 위상을 향상하는데 유용하다 가 4.06점, 일반적으로 의료기술은 환자 간호와 환 자의 안녕을 증진시킨다가 3.99점 순으로 나타났 다. 가장 낮게 반응한 문항은 수술 의료기술의 발 달로 간호사의 업무량이 늘어 났다로 2.12점이었 다.

자기효능감의 정도는 최저 41 점에서 최고 85 점 이었으며, 평균점수는 총 80점 만점에 64.318ะ 8.01 점이었으며, 평균평점은 5점 만점에 3.78점으로 나 타났다.

항목별로 세부적으로 분석하여 보면 <표 $4>$ 와 같이 제시할 수 있는데, 나는 나 자신을 신뢰한다 와 나는 내가 해야 할 일을 수행할 수 있다가 4.04 점으로 가장 높게 나타났으며, 가장 낮게 반응한 문항은 나는 예기치 못한 문제가 발생해도, 그러한 일들을 잘 처리할 수 있다로 3.48점으로 나타났다.

전문직 자아개념의 정도는 최저 52점에서 최고 
<표 2> 대상자의 의료기술에 대한 인지, 자기효능감 및 전문직 자아개념의 정도 $(\mathrm{N}=164)$

\begin{tabular}{lcccc}
\hline \multicolumn{1}{c}{ 변수 } & 최저 & 최고 & 평균 \pm 표준편차 & 평점평균 \pm 표준편차 \\
\hline \hline 의료기술에 대한 인지 & 32 & 68 & $47.88 \pm 5.78$ & $3.42 \pm 0.41$ \\
자기효능감 & 41 & 85 & $64.31 \pm 8.01$ & $3.78 \pm 0.47$ \\
전문직 자아개념 & 52 & 105 & $74.54 \pm 8.82$ & $2.76 \pm 0.33$ \\
-전문직 실무영역 & 31 & 63 & $45.04 \pm 6.18$ & $2.82 \pm 0.39$ \\
-만족감 & 7 & 27 & $17.69 \pm 3.96$ & $2.53 \pm 0.57$ \\
-의사소통 & 8 & 16 & $11.81 \pm 1.37$ & $2.95 \pm 0.34$ \\
\hline
\end{tabular}

\section{<표 3> 의료기술에 대한 인지 하부영역}

\begin{tabular}{|c|c|}
\hline 의료기술에 대한 인지 & 평균 표준편차 \\
\hline 1. 의료기술 및 장비의 발달로 환자를 간호하는 시간적 여유가 부족한 것 같다. & $3.08 \pm .98$ \\
\hline 2. 고도로 발달된 수술의료기술의 도입시 거기에 합당한 숙련된 기술이 필요하다. & $4.47 \pm .63$ \\
\hline 3. 수술의료기술의 발달로 간호사의 업무량이 늘어났다. & $2.12 \pm .96$ \\
\hline 4. 의료기술과 관련된 업무가 늘어남으로써 간호전문직의 가치가 절하되었다. & $3.52 \pm 1.02$ \\
\hline 5. 의료기술의 유입으로 수술실 간호사의 전문적 이미지가 향상되었다. & $3.61 \pm .91$ \\
\hline 6. 의료기술을 활용했음에도 불구하고 어쩔 수 없이 환자가 사망했을 경우 간호사는 자주 좌절감을 느끼게 된다. & $2.44 \pm .94$ \\
\hline 7. 의료기술의 사용이 때로는 환자에게 적절한 간호를 하는 데 방해가 되기도 한다. & $2.91 \pm .95$ \\
\hline 8. 의료기술의 유입이 많아짐에 따라 간호사는 종종 환자에게 소홀해지기 쉽다. & $2.84 \pm 1.01$ \\
\hline 9. 나는 의료기술이 임상에 주는 혜택에 대해 회의를 느낀다. & $3.47 \pm .97$ \\
\hline 10. 일반적으로 의료기술은 환자간호와 환자의 안녕을 증진시킨다. & $3.99 \pm .72$ \\
\hline 11. 의료기술의 발달은 수술실 간호사의 직업적 전문성에 회의를 느끼게 한다. & $3.65 \pm .85$ \\
\hline 12. 수술실 간호사가 의료기술의 사용에 숙달되면 근무환경을 감당하기가 수월해진다. & $3.80 \pm 1.10$ \\
\hline 13. 의료기술을 사용하는 것은 수술실 간호사의 업무에 의미를 부여한다. & $3.92 \pm .70$ \\
\hline 14. 의료기술을 능숙하게 활용하는 것은 수술실 간호사가 전문직업인으로서의 위상을 향상하는 데 유용하다. & $4.06 \pm .80$ \\
\hline
\end{tabular}

<표 4> 자기효능감 하부영역

\begin{tabular}{|c|c|}
\hline 자기효능감 & 평균 \pm 표준편차 \\
\hline 1. 나는 어떤 일을 계획할 때 그 일을 할 수 있다고 확신한다. & $3.84 \pm .71$ \\
\hline 2. 나는 내가 해야 할 일을 수행할 수 있다. & $4.04 \pm .49$ \\
\hline 3. 나는 어떤 일을 시작할 때 어려워도 끝까지 노력할 수 있다. & $3.77 \pm .76$ \\
\hline 4. 나는 스스로 중요한 목표를 세우면 그 목표를 성취할 수 있다. & $3.74 \pm .76$ \\
\hline 5. 나는 무엇을 하든지 그 일을 완성하기 전에 포기하지 않는다 & $3.57 \pm .78$ \\
\hline 6. 나는 어려운 일이라도 직면할 수 있다. & $3.48 \pm .89$ \\
\hline 7. 나는 복잡한 일이라도 해보려고 노력할 수 있다. & $3.73 \pm .76$ \\
\hline 8. 나는 즐겁지 못한 일이라도 해야 할 일이면 끝까지 그 일을 할 수 있다. & $3.93 \pm .75$ \\
\hline 9. 나는 할 일이 결정되면 즉시 시행할 수 있다. & $3.73 \pm .87$ \\
\hline 10. 나는 새로운 것을 배울 때, 처음에 성공하지 못하더라도 포기하지 않는다. & $3.76 \pm .81$ \\
\hline 11. 나는 예기치 못한 문제가 발생해도, 그러한 일들을 잘 처리할 수 있다. & $3.48 \pm .79$ \\
\hline 12. 나는 새로운 일이 어려워 보여도, 배우려고 노력할 수 있다. & $3.95 \pm .72$ \\
\hline 13. 나는 실패했을 때 좌절하지 않고 더욱 열심히 노력할 수 있다. & $3.67 \pm .82$ \\
\hline 14. 나는 어떤 일을 해내는 나의 능력에 자신이 있다. & $3.71 \pm .78$ \\
\hline 15. 나는 나 자신을 신뢰한다. & $4.04 \pm .75$ \\
\hline 16. 나는 쉽게 포기하지 않는다 & $3.92 \pm .70$ \\
\hline 17. 나는 일상생활에서 일어나는 문제들을 처리할 능력이 있다. & $3.96 \pm .63$ \\
\hline
\end{tabular}


105점이었으며, 평균점수는 총 108점 만점에 74.54점, 표준편차 8.82점으로 나타났다. 평균 평점 은 4점 만점에 2.76점으로 나타났다.

영역별 평균평점 순을 보면 의사소통 영역이 2.95점으로 가장 높은 점수를 나타냈으며, 전문직 실무영역이 2.82점, 만족감 영역이 2.53점 순으로 나타났다.

3. 수술실 간호사의 일반적 특성과 교육여부 에 따른 의료기술에 대한 인지와 자기효능 감 및 전문직 자아개념 차이

본 연구 대상자의 일반적 특성에 따른 제 요인 들의 차이를 검정한 결과는 <표 $5>$ 와 같다.

수술실 간호사의 일반적 특성에 따른 의료기술 에 대한 인지 차이는 연령 $(\mathrm{F}=8.462, \mathrm{p}=.000)$, 결혼 여부( $\mathrm{t}=1.939, \mathrm{p}=.054)$, 최종학력 $(\mathrm{t}=-2.220, \mathrm{p}=.028)$, 수술임상경력 $(\mathrm{F}=7.221, \quad \mathrm{p}=.000), \quad$ 직위 $(\mathrm{t}=3.474$, $\mathrm{p}=.001)$ 에 따라 통계적으로 유의한 차이를 보였다.

연령에 따른 의료기술에 대한 인지는 40 세 이상 이 53.15점으로 가장 높게 나타났으며, 30 39세가 48.82점, 29세 이하가 46.83점 순으로 나타났다. 결 혼여부에 따른 의료기술에 대한 인지는 기혼이 49.50점, 미혼이 47.24점으로 기혼이 미혼보다 의료 기술에 대한 인지가 높게 나타났으며, 최종학력에 따른 의료기술에 대한 인지는 학사 졸업 및 석사 과정 이상이 49.49점, 전문대 졸업이 47.27점으로 학사 졸업 및 석사과정 이상이 전문대 졸업보다 의료기술에 대한 인지가 높게 나타났다. 수술 임상 경력에 따른 의료기술에 대한 인지는 10 년 이상이 51.70 점으로 가장 높게 나타났으며, 1년 미만이 48.06점, 1 5년 미만이 47.07점, 5 10년 미만이 46.21점 순으로 나타났다. 직위에 따른 의료기술에 대한 인지는 책임간호사 및 수간호사가 51.82점, 일반간호사가 47.06점으로 책임간호사 및 수간호사 가 일반간호사보다 의료기술에 대한 인지가 높게
나타났다.

수술실 간호사의 일반적 특성에 따른 자기효능 감은 연령 $(\mathrm{F}=4.958, \mathrm{p}=.008)$, 최종학력 $(\mathrm{t}=-2.532$, $\mathrm{p}=.012)$, 수술임상경력( $\mathrm{F}=6.519, \mathrm{p}=.000)$, 직위 $(\mathrm{t}=3.233, \mathrm{p}=.001)$ 에 따라 통계적으로 유의한 차이 를 보였다.

연령에 따른 자기효능감은 40 세 이상이 70.53점 으로 가장 높게 나타났으며, 30 39세가 64.73점, 29세 이하가 63.37점 순으로 나타났다. 최종학력에 따른 자기효능감은 학사 졸업 및 석사과정 이상이 66.85점, 전문대 졸업이 63.35점으로 학사 졸업 및 석사과정 이상이 전문대 졸업보다 자기효능감이 높게 나타났다. 수술 임상경력에 따른 자기효능감 은 10년 이상이 69.37점으로 가장 높게 나타났으 며, 5 10년 미만이 64.00점, 1 5년 미만이 62.81 점 순으로 나타났다. 직위에 따른 자기효능감은 책 임간호사 및 수간호사가 68.84점, 일반간호사가 63.42점으로 책임간호사 및 수간호사가 일반간호사 보다 자기효능감이 높게 나타났다.

수술실 간호사의 일반적 특성에 따른 전문직 자 아개념은 연령( $\mathrm{F}=11.976, \mathrm{p}=.000)$, 결혼여부 $(\mathrm{t}=3.033$, $\mathrm{p}=.003)$, 최종학력 $(\mathrm{t}=-4.020, \mathrm{p}=.000)$, 수술임상경력 $(\mathrm{F}=21.07, \mathrm{p}=.000)$, 직위 $(\mathrm{t}=5.984, \mathrm{p}=.000)$ 에 따라 통 계적으로 유의한 차이를 보였다.

연령에 따른 전문직 자아개념은 40 세 이상이 82.16점으로 가장 높게 나타났으며, 30 39세가 77.47점, 29세 이하가 72.36점 순으로 나타났다. 결 혼여부에 따른 전문직 자아개념은 기혼이 77.29점, 미혼이 73.03점으로 기혼이 미혼보다 전문직 자아 개념이 높게 나타났으며, 최종학력에 따른 전문직 자아개념은 학사 졸업 및 석사과정 이상이 78.85 점, 전문대 졸업이 72.91점으로 학사 졸업 및 석사 과정 이상이 전문대 졸업보다 전문직 자아개념이 높게 나타났다. 수술 임상경력에 따른 전문직 자아 개념은 10 년 이상이 82.82 점으로 가장 높게 나타났 으며, 5 10년 미만이 74.87점, 1 5년 미만이 
72.29점 순으로 나타났다. 직위에 따른 전문직 자 아개념은 책임간호사 및 수간호사가 82.79점, 일반 간호사가 72.84점으로 책임간호사 및 수간호사가 일반간호사보다 전문직 자아개념이 높게 나타났다.

수술실 간호사의 근무하는 병원의 의료기술 도
입시 교육여부와 계속적인 교육여부 및 교육매뉴 얼 여부에 따른 의료기술에 대한 인지, 자기효능감 및 전문직 자아개념의 차이는 통계적으로 유의한 차이를 보이지 않는 것으로 나타났다.

<표 5> 일반적 특성에 따른 의료기술에 대한 인지와 자기효능감 및 전문직 자아개념 차이 $(\mathrm{N}=164)$

\begin{tabular}{|c|c|c|c|c|c|c|c|}
\hline \multirow[b]{2}{*}{ 특성 } & \multirow[b]{2}{*}{ 변수 } & \multicolumn{2}{|c|}{ 의료기술에 대한 인지 } & \multicolumn{2}{|c|}{ 자기효능감 } & \multicolumn{2}{|c|}{ 전문직 자아개념 } \\
\hline & & 평균(표준편차) & $\begin{array}{l}t \text { or } F \\
\text { (p) }\end{array}$ & 평균(표준편차) & $\begin{array}{l}\mathrm{t} \text { or } \mathrm{F} \\
\text { (p) }\end{array}$ & 평균(표준편차) & $\begin{array}{l}\text { t or } F \\
\text { (p) }\end{array}$ \\
\hline \multirow[t]{2}{*}{ 성별 } & 남 & $50.80(10.28)$ & -.65 & $67.40(11.59)$ & -.88 & $\overline{777.00(11.73)}$ & -.48 \\
\hline & 여 & 47.79(5.62) & .549 & $64.21(7.90)$ & .383 & $74.46(8.76)$ & .655 \\
\hline \multirow[t]{3}{*}{ 연령(세S) } & $\sim 29 \quad a$ & 46.83(5.16) & 8.46 & 63.37(7.97) & 4.96 & 72.36(7.84) & 11.98 \\
\hline & $30 \sim 39 \quad b$ & $48.82(5.86)$ & $000 *$ & $64.73(7.87)$ & $.008 *$ & 77.47(9.72) & $.000 *$ \\
\hline & Above $40 \mathrm{c}$ & $53.15(7.20)$ & $c>a, b$ & 70.53(6.05) & $c>a$ & $82.16(6.09)$ & $b, c>a$ \\
\hline \multirow[t]{2}{*}{ 결혼여부 } & 기혼 & 49.50(6.36) & 1.94 & $65.21(8.68)$ & 1.06 & $77.29(9.82)$ & 3.03 \\
\hline & 미혼 & $47.24(5.36)$ & $.054 *$ & $63.82(7.61)$ & .291 & 73.03(7.88) & $.003 *$ \\
\hline \multirow[t]{2}{*}{ 종교 } & 유 & 47.64(6.27) & -.50 & $65.00(8.06)$ & .98 & 74.62(9.55) & 9.55 \\
\hline & 무 & 48.09(5.29) & .622 & 63.78(7.85) & .327 & $74.53(8.10)$ & 8.10 \\
\hline \multirow{2}{*}{ 교육정도 } & 전문대 & $47.27(5.99)$ & -2.22 & 63.35(7.92) & -2.53 & $72.91(8.27)$ & -4.02 \\
\hline & 학사졸 이상 & $49.49(4.90)$ & $.028 *$ & $66.85(7.78)$ & $.012 *$ & 78.85(8.89) & $.000 *$ \\
\hline \multirow{4}{*}{ 경력(년) } & Below 1 a & 48.06(4.28) & 7.22 & $61.56(5.03)$ & 6.52 & $67.17(4.32)$ & 21.07 \\
\hline & $1 \sim 5 \quad b$ & 47.07(5.05) & $.000 *$ & $62.81(8.56)$ & $.000 *$ & $72.29(7.57)$ & $.000 *$ \\
\hline & $5 \sim 10$ & $46.21(6.10)$ & $d>b, c$ & $64.00(7.69)$ & $d>a, b, c$ & $74.87(7.89)$ & $d>a$ \\
\hline & Above $10 \mathrm{~d}$ & $51.70(6.12)$ & & $69.37(6.52)$ & & 82.82(8.31) & \\
\hline \multirow[t]{2}{*}{ 지위 } & 수간호사 및 책임간호사 & $51.82(6.85)$ & 3.47 & $68.84(8.06)$ & 3.23 & 82.79(8.65) & 5.98 \\
\hline & 일반간호사 & 47.06(5.21) & $.001 *$ & $63.42(7.73)$ & $.001 *$ & $72.84(7.88)$ & $.000 *$ \\
\hline \multirow{3}{*}{$\begin{array}{l}\text { 초기의 료기 } \\
\text { 술교육여부 }\end{array}$} & 실시한다 & $48.23(5.68)$ & 2.33 & $64.81(7.57)$ & 1.31 & $74.89(8.81)$ & .54 \\
\hline & 실시하지않는다 & $48.45(6.38)$ & .101 & $63.91(10.42)$ & .272 & $72.36(10.75)$ & .583 \\
\hline & 일부관리자만 한다 & $45.65(5.76)$ & & 62.04(8.92) & & 73.73(8.20) & \\
\hline \multirow{2}{*}{$\begin{array}{l}\text { 계 속의 료기 } \\
\text { 술교육여부 }\end{array}$} & 실시한다 & 48.04(5.64) & .79 & $64.78(7.68)$ & 1.70 & 74.76(8.72) & .73 \\
\hline & 실시하지않는다 & 47.07(6.53) & .431 & 61.93(9.31) & .090 & $73.41(9.44)$ & .469 \\
\hline \multirow{2}{*}{$\begin{array}{l}\text { 교육매뉴얼 } \\
\text { 비치여부 }\end{array}$} & 비치되어있다. & $48.00(5.82)$ & .58 & $64.52(7.65)$ & .62 & 74.62(8.76) & .24 \\
\hline & 비치되어있지않다. & 47.31(5.66) & .56 & 63.35(9.61) & .54 & 74.17(9.27) & .81 \\
\hline
\end{tabular}

* $p<.05, * * p<.001$ 
4. 수술실 간호사의 의료기술에 대한 인지, 자 기효능감, 전문직 자아개념과의 상관관계

수술실 간호사의 의료기술에 대한 인지, 자기효 능감, 전문직 자아개념과의 상관관계는 <표 6>과 같다.

의료기술에 대한 인지와 자기효능감 및 전문직 자아개념 간의 상관관계는 각각 $\mathrm{r}=.197(\mathrm{p}<.05)$, $\mathrm{r}=.222(\mathrm{p}<.001)$, 자기효능감과 전문직 자아개념간 의 상관관계는 $\mathrm{r}=.609(\mathrm{p}<.001)$ 로 변수 상호간 유 의하게 긍정적인 관계가 있는 것으로 나타났다.

〈표 6> 대상자의 의료기술에 대한 인지, 자기효능감, 전문직 자아개념과의 상관관계 $(\mathrm{N}=164)$

\begin{tabular}{lcc}
\hline \multicolumn{1}{c}{ 변수 } & 의료기술에 대한 인지 & 자기효능감 \\
\hline \hline 자기효능감 & $.197 *$ & \\
전문직 자아개념 & $.222 * \star$ & $.609 * \star$ \\
\hline$* 0<05 * \star *<001$ & &
\end{tabular}

\section{IV. 고찰 및 제언}

\section{1. 고찰}

본 연구는 의료기술을 자주 접하고 있는 수술실 간호사들의 의료기술에 대한 인지, 자기효능감 및 전문직 자아개념을 알아보고, 각 변수들 간의 상관 관계를 조사한 연구이다. 의료기술에 대한 인지정 도는 평균 평점 5점 만점에 3.42점으로, 이는 연변 지역 간호사를 대상으로 한 노춘희 외[13]의 2.93 점보다는 높았으나, 임상간호사를 대상으로 한 노 춘희와 송경애[12]의 3.48점, 수술실 간호사를 대상 으로 한 이경희[9]의 3.87점보다는 낮게 나타났다. 이러한 결과는 본 연구의 대상자가 일반병동보다 의료기술을 접하는 빈도가 잦고 의료기술에 많이 노출되는 수술실에 근무하지만, 의료기술을 접하는
빈도와 교육의 기회 여부에 따른 결과로 파악된다.

의료기술에 대한 인지가 가장 높은 문항은 고도 로 발달된 수술 의료기술의 도입 시 거기에 합당 한 숙련된 기술이 필요하다. 의료기술을 능숙하게 활용하는 것은 수술실 간호사가 전문직업인으로서 의 위상을 향상하는데 유용하다. 의료기술은 환자 간호와 환자의 안녕을 증진시킨다 순으로 나타났 으며, 이는 이경희[9]의 연구와 일치하였다. 또한 가장 낮은 점수 문항은'수술 의료기술의 발달로 간 호사의 업무량이 늘어났다'로 나타났는데 이는 계 속적으로 발달되는 의료기술의 적용은 간호사의 업무 즉, 습득해야할 기술과 관리부분에서 중요한 비중을 차지하고 있음을 의미한다. 첨단 의료 환경 에서 간호사가 익혀야할 의료기술은 계속 변화하 고 있어 단순히 업무가 증가한 것으로 느껴지고 간호사에게 스트레스로 작용할 수 있으나, 전문직 간호사로서 의료기술에 대한 긍정적인 인지와 환 자 간호 및 업무수행 향상을 위한 의료기술과 관 련된 실무교육이 강화되어야 한다.

자기효능감 정도는 평균 평점 5점 만점에 3.78 점으로, 이는 임상간호사를 대상으로 연구한 김미 경[6]의 3.43점, 정애순[19]의 3.56점과 최소라[23]의 3.49점보다 높게 나타나 수술실 간호사가 일반병동 간호사보다 자기효능감이 높음을 알 수 있다. 자기 효능감의 정도가 가장 높은 문항은 '나는 나 자신 을 신뢰한다', '나는 내가 해야 할 일을 수행할 수 있다'로 나타났으며, 가장 낮은 점수 문항은 '나는 예기치 못한 문제가 발생해도, 그러한 일들을 잘 처리할 수 있다로 나타났다. 이는 김미경[6]과 정 애순[19]의 연구결과와 일치하였다. 이러한 결과는 대상자가 수술실 간호사로서 간호 전문직에 대해 스스로 자신감을 갖고 업무에 임하고 있으나, 응급 상황의 원활한 대처에 대한 불안감과 스트레스로 양가감정을 가지고 있음을 알 수 있었고, 이를 극 복하기 위해서는 주위환경을 인식하고 그 환경에 적응하는 노력과 지속적인 자기계발이 필요하다. 
전문직 자아개념의 정도는 평균 평점 4 점 만점 에 2.76점, 이 결과는 임상간호사를 대상으로 한 이승희[10]의 2.71점, 장희정 등[8]의 2.74점, 신장실 간호사를 대상으로 한 최은영과 김건효[7]의 2.73 점보다 높았으나, 수술실 간호사를 대상으로 한 이 경희[9]의 2.82점, 임상 간호사를 대상으로 한 박보 근[24]의 2.78점, 송경애와 노춘희[20]의 2.79점보다 는 낮게 나타났다. 이는 간호사들의 근무기관이나 근무 환경, 직업에 대한 신념과 태도, 직업의 만족 과 업무성과 등에 따라 달라지는 것으로 이해할 수 있다. 또한 호주 간호사를 대상으로 한 Arthur[16]의 연구에서는 3.41점, 캐나다 간호사를 대상으로 한 Arthur와 Thorne[25]의 연구에서는 3.42점으로 나타나 우리나라 간호사들의 전문직 자 아개념이 외국보다 낮은 수준에 머물러 있음을 알 수 있다. 이는 우리나라 간호사의 근무환경이 외국 에 비해 전문직으로서 자율성 및 확고한 위치를 차지하지 못하고 있으므로 올바른 직업관과 긍정 적인 전문직 자아개념의 형성을 저해하는 결과를 초래했다고 생각된다. 그러므로 전문직 자아개념을 높이기 위한 프로그램과 제도가 필요하겠다.

전문직 자아개념의 하위 영역별 점수는 의사소 통 영역이 2.95점, 전문적 실무영역이 2.82점, 만족 감 영역이 2.53점 순으로 나타났다. 이 결과는 동 일 부서를 대상으로 한 이경희[9]의 연구와 일치하 였다. 간호사의 전문직 자아개념 중 의사소통 영역 의 점수가 높게 나온 것은 수술실 간호사들이 환 자와 동료들과 공감하고 있으며 열린 마음의 자세 를 가지고 있음을 알 수 있다. 또한 의사소통이나 전문적 실무보다 만족감 영역이 가장 낮은 것은 수술실 간호사는 일반병동보다 위험 노출이 잦고, 정신적 긴장감과 장시간 서있는 자세로 일해야 함 에도 불구하고 근무환경에 대한 고려가 적절하지 않기 때문이라 생각된다. 따라서 이에 대한 계속적 인 연구를 통해 수술실 간호사가 가진 불만족 요 인을 파악하고 이를 개선하기 위한 연구가 필요할
것으로 생각된다.

수술실 간호사의 일반적 특성에 따른 의료기술 에 대한 인지를 분석한 결과, 연령, 결혼여부, 최종 학력, 수술임상경력, 직위에 따라 통계적으로 유의 한 차이를 보였다. 이 결과는 결혼한 간호사와 특 수부서에 근무하는 간호사일수록 유의한 차이를 보인 노춘희와 송경애[12], 노춘희 등[13]의 연구와 부분적으로 일치하였다. 이는 연령 및 수술 임상경 력이 높을수록, 기혼이고 학력 및 직위가 높은 간 호사일수록 의료기술을 접하는 기회와 경험이 풍 부하여 의료기술에 대한 인지가 긍정적이므로, 낮 은 근무경력과 경험이 적은 일반 간호사에게 다양 한 의료기술을 접할 수 있는 기회마련을 통한 동 기부여가 필요할 것이다.

일반적 특성에 따른 자기효능감을 분석한 결과 는 연령, 최종학력, 수술임상경력, 직위에 따라 통 계적으로 유의한 차이를 보였다. 이 결과는 김미경 [6]의 연구결과와 일치하였으며, 연령, 결혼여부, 최종학력, 임상경력, 직위에 유의한 차이를 보인 임세영[3], 이경희[9], 정애순[19]의 결과와 부분적 으로 일치하였다. 이는 연령, 학력 및 직위가 높고, 수술 임상경력이 많을수록 실무경력이 쌓이면서 지식 축적 및 전문성이 높아지며, 또한 간호현장에 서 간호실무 및 대인관계에서 충분한 능력을 발휘 하고 자신감을 갖게 되는 것으로 파악할 수 있었 다.

일반적 특성에 따른 전문직 자아개념을 분석한 결과는 연령, 결혼여부, 최종학력, 수술임상경력, 직위에 따라 유의한 차이를 보였다. 이는 연령, 결 혼여부, 최종학력, 임상경력, 직위 등의 일반적 특 성에 유의한 차이를 보인 임세영[3], 김수연[4], 이 경희[9]와 일관된 결과를 나타내었다.

전문직 자아개념의 하위 영역별 점수비교에서는 의사소통 영역이 2.95점으로 가장 높게 나타났으 며, 만족감 영역이 2.53점으로 가장 낮게 나타났다. 이경희[9]의 연구에서 의사소통영역이 2.9점으로 
가장 높고, 만족감 영역이 2.68점으로 가장 낮게 나타난 것과 일치하는 연구결과를 보인다. 또한 최 은영과 김건효[7]의 연구에서도 의사소통 영역이 3.0점으로 가장 높고 만족감이 2.46점으로 가장 낮 게 나타나 본 연구결과와 일치하는 것으로 사료된 다. 간호사들의 의사소통 영역이 높게 나타나는 것 은 간호사들이 대상자와 의사소통을 하려고 하는 열린 마음을 가지고 있음을 의미한다고 생각하며 만족감 영역이 낮은 것은 간호사들의 위험노출이 많고 정신적인 긴장상태가 지속되며 계속 서있는 자세로 일해야 하는 등 신체적인 스트레스가 많기 때문으로 사료된다.

의료기술 교육여부에 따른 의료기술에 대한 인 지, 자기효능감 및 전문직 자아개념의 차이는 유의 하지 않았다. 이 결과는 의료기술에 대한 지속적인 교육이 간호사들의 신 의료기술에 대한 긍정적인 인식과 자기효능감 및 전문직 자아개념에 영향을 미친 이경희[9]의 연구 결과와 다르게 나타났다. 이는 계속 변화하는 수술현장에서 의료기술에 대 한 정보의 공유정도와 교육의 방법에 따라 영향을 받을 것으로 예상된다. 특히 신규 간호사의 경우 간호이론과 실무의 차이로 임상 적응에 많은 어려 움이 따르며, 실무기술이 능숙하지 못해 스트레스 를 받고 이로 인해 자신감이 결여된다. 그러므로 전문화된 간호요구를 충족시키고 양질의 간호를 제공하기 위해서 간호이론과 임상에서의 차이를 최소화하고, 간호사들의 실무능력과 자신감 향상을 위한 지속적이고 표준화된 교육 프로그램이 필요 할 것이다.

수술실 간호사의 의료기술에 대한 인지, 자기효 능감, 전문직 자아개념과의 상관관계에서 의료기술 에 대한 인지와 전문직 자아개념은 순 상관관계로 나타났는데, 이 결과는 이경희[9], 노춘희와 송경 애[12], 노춘희 등[13]의 연구와 일치하였다. 또한 자기효능감은 의료기술에 대한 인지와의 관계에서 순 상관관계를 보여주었고, 전문직 자아개념과도
비교적 높은 순 상관관계로 나타났는데, 이 결과는 자기효능감이 높을수록 의료기술에 대한 인지가 높고[8], 전문직 자아개념이 높다고 보고한 임세영 [3], 최은영과 김건효[7], 장희정 등[8], 이경희[9], 이승희[10]와 유사한 결과를 나타냈다. 이는 의료 기술에 대한 인지가 긍정적일수록 전문직 자아개 념이 잘 형성되고, 자기효능감이 높을수록 의료기 술에 대한 인지와 전문직 자아개념이 높아짐을 보 여준다. 따라서 수술실 간호사의 의료기술에 대한 긍정적인 인지와 자기효능감은 전문직 자아개념의 향상과 수술 간호 업무의 성과를 높이는 동시에 양질의 간호 서비스로 고객 감동과 병원의 효율성 을 극대화 시킬 수 있다고 생각된다. 그러므로 의 료기술에 대한 인지와 자기효능감을 향상시키는 프로그램을 개발하여 체계적인 교육을 계속적으로 실시함으로써 수술실 간호사들의 전문직 자아개념 을 확고히 해야 할 필요가 있다고 생각된다.

이상의 연구결과를 종합해보면 수술실 간호사들 은 의료기술 발달에 대한 긍정적 평가와 함께 간 호전문직 발전에도 영향을 주고 있음을 지각하고 있으며, 간호사들의 의료기술에 대한 인지와 자기 효능감은 전문직 자아개념에 중요한 영향을 미치 는 것을 알 수 있었다. 따라서 계속적으로 변화하 는 수술환경에서 의료기술에 대한 정보제공과 체 계적인 교육, 즉 이론과 실기교육의 조화로 수술실 간호사의 전문적 실무 및 자신감의 향상과 전문 의료인으로서 의료기술을 긍정적으로 인식할 수 있도록 해야 한다. 또한 자기효능감을 증진시키는 프로그램을 개발하고 이를 지속시키기 위한 정책 도 마련되어야 할 것이다. 이러한 노력의 결과로 수술실 간호사의 전문직 자아개념은 향상될 것이 며 이를 통해 수술 간호의 전문성 및 질적 향상을 도모하고 간호 전문직 발전에 기여할 수 있을 것 이다. 
2. 제언

본 연구 결과를 토대로 다음과 같이 제언하고자 한다.

(1) 변화하는 의료기술에 대한 간호사의 긍정적 인 인지와 자기효능감을 증진시켜 전문직 자아개 넘을 향상시킬 수 있는 교육 프로그램을 개발하고 그 효과를 검증할 필요가 있다.

(2) 본 연구는 연구의 표본이 수술실 간호사로 제한적이므로 대상자를 일반병동 간호사로 확대하 여 반복 또는 비교연구 할 필요가 있다.

\section{참고문헌}

1. 정귀수, 차력(2009), 국내 의료서비스업의 향후 시 장성장 전망, 하나금융경영연구소, 산업연구시리 즈, p.14.

2. 채보민(2008), 수술장에 첨단기술 도입과 수술장 간호사에게 미칠 영향, 수술간호, Vol. 16(1); 260-266.

3. 임세영(2009), 수술실 간호사의 전문직 자아개념, 자기효능감과 직무만족, 한림대학교 대학원 석사 학위논문, pp.1-19.

4. 김수연(2002), 수술실 간호사의 전문직 자아개념, 비판적 사고성향과 간호 업무 수행에 관한 연구, 고려대학교 교육대학원 석사학위논문, pp. 1-3.

5. Virginia E., \& Susan E.(1996), Improving self efficiency in Nursing Research, Clinical Nurse Specialist, Vol.10(2);832.

6. 김미경(2008), 간호사의 윤리적 딜레마, 자기효능 감이 직무만족도에 미치는 영향, 조선대학교 대학 원 석사학위논문, pp.7-26.

7. 최은영, 김건효(2000), 신장실 간호사의 전문직 자 아개념, 자기 효능감과 직무 만족도에 관한 연구, 성인간호학회지, Vol.12(3);345-354.
8. 장희정, 양순옥, 이명옥(2007), 전문 간호사 요구에 따른 간호사의 자기 효능감, 전문직 자아개념, 대 한간호학회지, Vol.14(1);110-119.

9. 이경희(2009), 수술실 간호사의 신 의료기술에 대 한 인식과 자기 효능감 및 전문직 자아개념과의 관계, 연세대학교 대학원 석사학위논문, pp. 38-39. 10. 이승희(2008), 임상간호사의 전문직 자아개념, 자 기효능감과 직무만족에 관한 연구, 성인간호학회 지, Vol.20(1);10-20.

11. 노춘희, 송경애(1999), 의료기계 장비발달의 영향 과 돌봄의 속성에 대한 간호사의 지각, 한국 보건간호학회지, Vol.13(2);84-100.

12. 노춘희, 송경애(2000), 의료기술발달에 대한 간호 사의 지각과 전문직 자아개념, 대한간호학회지, Vol.30(5);1368-1378.

13. 노춘희, 김경애, 이춘옥, 이진숙, 김수지, 송경애 (2003), 연변지역 간호사의 의료기술발달과 돌봄의 속성에 대한 지각 및 전문직 자아 개념, 대한간호 학회지, Vol.33(3);356-364.

14. 한경희(2006), 고가의료장비의 현황분석 및 관리 방안연구, 서울대학교 보건대학원 석사학위논문, pp.4-6.

15. Bandura A.(1986), Social Foundations of thought and action, A Social Cognitive theory, Englewood Cliffs, New Jersey, Prentice-Hall, pp.390-453.

16. Arthur D.(1992), Measuring the professional self-concept of nurses: a critical review, Journal of Advanced Nursing, Vol.17(6);712-719,

17. Arthur D., Pang S., Wong T., Alexander M.F. Drury J., Eastwood H., Johansson I., Jooste K., Naude M., Noh C. H., O'Brien A., Sohng K.Y., Stevenson G.R., Sy-Sinda M.T., Thorne S., Van der Wal D. \& Xiao S.(1999), Caring attibutes, Professional self concept and technological influences in a sample of registered nurses in eleven countries, international Journal of Nursing Studies, Vol.36;387-396. 
18. Sherer M., Maddux J.E., Mercandante B., Prentice-Dunn S., Jacobs B. \& Rogers R.W.(1982), The self efficacy scale construction and validation, Psychological reports, pp.663-671.

19. 정애순(2007), 간호사의 건강증진행위와 자기 효 능감의 관계연구, 한양대학교 행정대학원 석사학 위논문, pp.17-18;23-57.

20. 송경애, 노춘희(1996), 임상간호사의 전문직 자아 개념에 관한 연구, 대한간호학회지, Vol.26(1);94106.

21. Halm M.A. \& Apen M.A.(1993), The impact of technology on patients and families, Nursing Clinics of North America, Vol.28(2);443-457.

22. Sinclair V.(1988), High technology in critical care, nursing implication for nursing's role and practice, Focus on Critical Care, Vol.15(4);36-41.

23. 최소라(2006), 간호사의 건강증진 생활양식에 미 치는 영향요인, 경희대학교 교육대학원 석사학위 논문, pp.27-33.

24. 박보근(2001), 종합병원 간호사의 전문직 자아개 념과 간호업무 수행에 관한 연구, 경희대학교 행 정대학원 석사학위논문, pp.22-26;28-29.

25. Arthur D. \& Thorne S.(1995), Professional self-concept of Nursing, A comparitive study of four strate of nursing in Canadian University, Journal of Nursing Education, Vol.34(3);105-108.

접수일자 2011년 8월 29일

심사일자 2011년 10월 12일

게재확정일자 2012년 2월 21일 